\title{
Ce-Ni (Cerium-Nickel)
}

\section{H. Okamoto}

The Ce-Ni phase diagram in [Massalski2] was adopted from [1991Nas]. [2005Oka] updated this phase diagram according to the thermodynamic evaluation by [2004Du]. Six intermetallic phases existing in this system were treated as line compounds.

[2007Xio] noticed that the $\mathrm{CeNi}_{5}$ phase has a measurable homogeneity range according to [1994Kim]. [2007Xio] confirmed this observation experimentally and calculated the $\mathrm{Ce}-\mathrm{Ni}$ phase diagram, as shown in Fig. 1. (The range below $200{ }^{\circ} \mathrm{C}$ was added by this evaluator.)

Earlier, [2004Pal] also calculated the $\mathrm{Ce}-\mathrm{Ni}$ phase diagram, but the $\mathrm{CeNi}_{5}$ phase was treated as a line compound.

\section{References}

1991Nas: P. Nash and C.H. Tung, Ce-Ni (Cerium-Nickel), Phase Diagrams of Binary Nickel Alloys, P. Nash, Ed., ASM International, 1991, p 62-67
1994Kim: D.Y. Kim, M. Ohtsuka, and K. Itagaki, Shigen-toSozai, 1994, 110, p 95-101, as quoted in [2007Xio]

2004Du: Z. Du, L. Yang, and G. Ling, Thermodynamic Assessment of the Ce-Ni System, J. Alloys Compd., 2004, 375, p 186190

2004Pal: M. Palumbo, G. Borzone, S. Delsante, N. Parodi, G. Cacciamani, R. Ferro, L. Battezzati, and M. Baricco, Thermodynamic Analysis and Assessment of the Ce-Ni System, Intermetallics, 2004, 12, p 1367-1372

2005Oka: H. Okamoto, Ce-Ni (Cerium-Nickel), J. Phase Equilib. Diffus., 2005, 397

2007Xio: W. Xiong, Y. Du, X. Lu, J.C. Schuster, and H. Chen, Reassessment of the Ce-Ni Binary System Supported by Key Experiments and Ab Initio Calculations, Intermetallics, 2007, 15, p 1401-1408

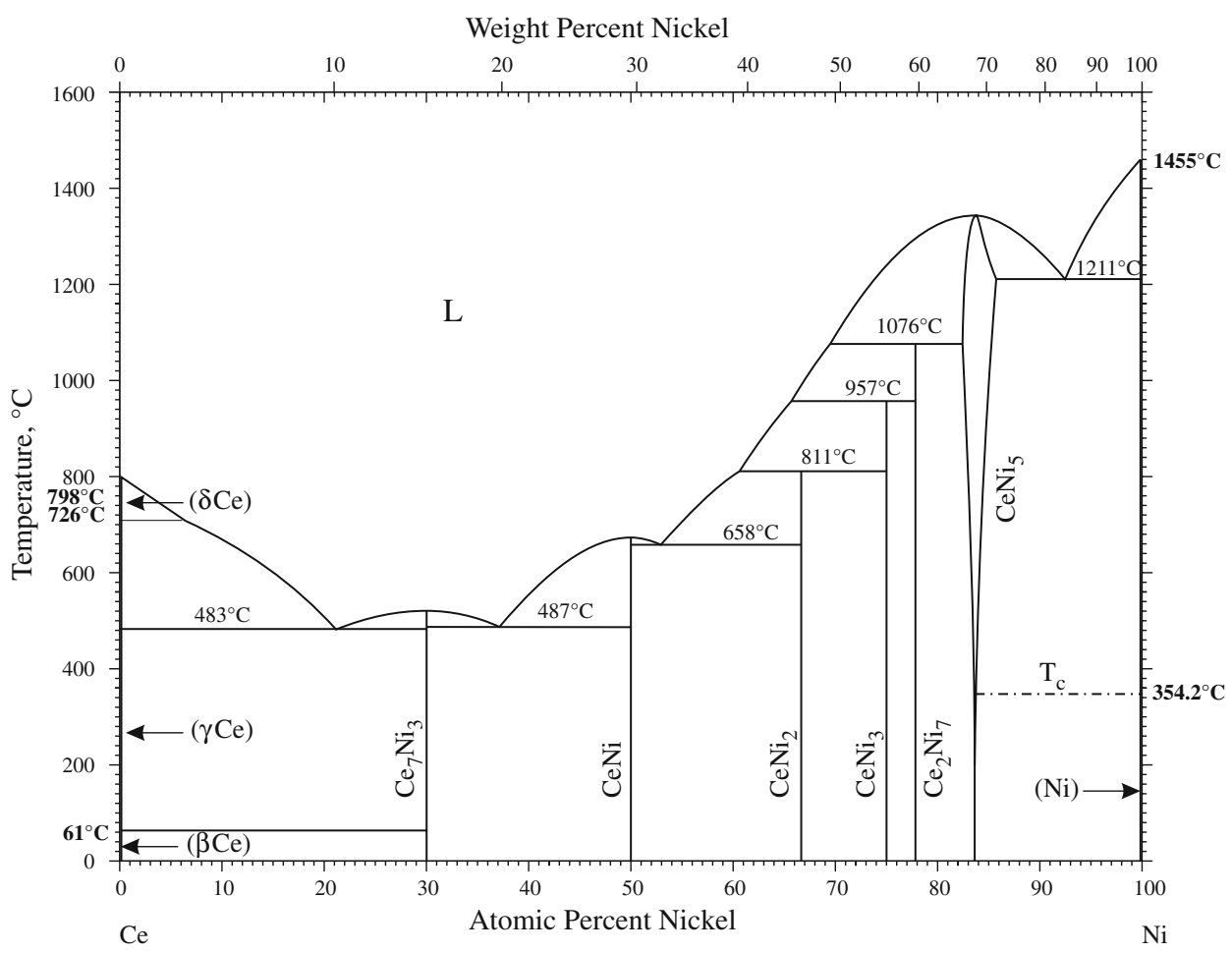

Fig. 1 Ce-Ni phase diagram 